\title{
EL MONASTERIO CISTERCIENSE DEL REAL DE MURCIA. UN PROYECTO FRACASADO DE JAIME II
}

\author{
REGINA SAINZ DE LA MAZA LASOLI \\ Institución Milá y Fontanals. CSIC. Barcelona
}

Aparte de los grandes monasterios cistercienses que desde la primera mitad del siglo XII encontramos diseminados por gran parte de la Península Ibérica, hubo también fundaciones que, por diversas circunstancias, fracasaron al poco de nacer o tuvieron una vida efímera, y de las que la historiografía apenas se ha ocupado.

Una de estas tentativas de fundación partió de la iniciativa de Jaime II y, de haber prosperado, hoy el Cister estaría presente en Murcia, concretamente en el real de la capital, donde el monarca instituyó el monasterio(1). De él únicamente el historiador Ferrán García nos da alguna noticia, basándose sólo en un documento fechado el 24 de mayo de 1297(2). El desconocimiento seguía, pues, siendo casi total hasta hoy, en que el hallazgo en el Archivo de la Corona de Aragón de varios documentos referentes a dicha fundación monástica, nos permite dar a conocer las circunstancias que la motivaron y las dificultades de sobrevivencia que la llevaron a su rápida extinción.

\section{FUNDACION}

Fue el 4 de julio de 1296 cuando Jaime II, tras la ocupación de toda la región septentrional de Murcia y cuando se encontraba en plena conquista de Elche, decidió proceder a la fundación de un monasterio del Cister en la ciudad de Murcia. El monarca declaraba que tomaba esta iniciativa movido 
por el especial afecto que él y sus progenitores sentían por el Cister y especialmente por el monasterio de Santes Creus, del que quería que el nuevo monasterio fuese filial. No en vano allí estaba enterrado su padre Pedro el Grande y también en Santes Creus había elegido él su sepultura. Además, dejaba constancia de que efectuaba la fundación en honor de Cristo y de la Virgen, y para lograr la remisión de sus pecados y la salvación de su alma y la de sus parientes. Consideramos, sin embargo, que estas motivaciones piadosas fueron las principales, pero no las únicas, y que los condicionantes históricos tuvieron bastante que ver con la gestación del proyecto. Así pues, creemos que Jaime II, con la creación del monasterio, perseguía también el objetivo, práctico e inmediato, de disponer de los brazos necesarios para garantizar la explotación y administración del territorio que rodeaba la ciudad de Murcia, recién incorporada a su reino, ciudad a la que, además, la presencia del Cister otorgaría un rango especial. Por último, el deseo de prestigio debió asimismo de estar presente en la mente del monarca a la hora de proyectar el nuevo monasterio que, sin duda, consolidaría su poder como rey.

El 4 de julio de 1296 constituye, pues, el punto de partida de la brevísima historia del monasterio murciano. Aquel día Jaime ll cursó tres cartas necesarias para afirmar su proyecto, puesto que, al constituir éste una fundación del Cister, entraba a formar parte del engranaje típico de los monasterios de esta Orden, en que cada uno de ellos dependía de su inmediato fundador. Él quería que el monasterio de Murcia fuese filial del de Santes Creus, el cual, a su vez, lo era del de Grandselve, dependiendo ambos de la abadía madre de Citeaux. Así pues, fue Bertrán, abad de Grandselve, el destinatario de la primera carta, a quien daba a conocer su proyecto, para el cual le pedía tuviera a bien concederle ciertas posesiones y bienes que el rey Alfonso $X$ de Castilla habia otorgado a un monasterio que construyó en Murcia. Nosreferimos al Monasterio de Santa María la Real, mandado construir por el rey castellano en 1277 tras la conquista, y que fue destruido por su hijo Sancho IV.(3) Jaime II pedía al abad le concediera aquellos bienes que habían sido distribuidos a diversas personas por Sancho IV, puesto que él no podía apropiarse de ellos "absque gravi gentium scandaIo". Una segunda carta a Rufino, abad de Citeaux o Cister, y a todo el capítulo de la Orden, pidiéndoles su consejo y consentimiento para llevar a cabo la nueva fundación(4). Una tercera carta iba dirigida a su tía, la reina Violante de Castilla, a la que le solicitaba le otorgara en usufructo los bienes que tenía en Alcantarilla, Alguazas, Molina Seca y en el real de Monteagudo para poder asignar a la nueva construcción(5). La finalidad que perseguía Jaime II con todas estas peticiones era asegurar los bienes que otorgaba al monasterio para que éste gozara de entera independencia y no se produjese nunca ningún tipo de reivindicación. 


\section{PATRIMONIO DEL MONASTERIO}

Por medio de otra carta, la cuarta fechada aquel 4 de julio de 1296, Jaime II señalaba y enumeraba detalladamente todos los bienes que asignaba "ad fundandam abbatiam Cisterciensis Ordinis apud Murcia" y su valor, bienes que pertenecían a la reina de Castilla, a saber(6):

- El real de Murcia, con huerto, casas, baños y pertenencias, cuya renta anual ascendía a 1200 morabetinos de Castilla, y que era, además, el lugar escogido para levantar el monasterio. Por dos de sus partes limitaba con la muralla de la ciudad, y por las otras dos con el mercado y el huerto de un tal Simón.

- Alcantarilla, con sus derechos y pertenencias, que especificaba y limitaba, y cuyas rentas alcanzaban un valor anual de 3500 morabetinos.

- El real de Monteagudo, de 2000 morabetinos anuales de renta.

- Alguazas de Molina, el valor de cuyas rentas era de 4.500 morabetinos.

- Heredad de María Fernández, viuda de García Jofré, con sus derechos y pertenencias, el valor de los cuales era de 4000 morabetinos de Castilla.

- la mitad de los molinos del alcázar, de 2000 morabetinos anuales de renta.

Así pues, la renta global de todas las posesiones mencionadas ascendía a 17.200 morabetinos anuales.

Después de estos documentos fundacionales, las fuentes guardan silencio durante unos meses. No podemos olvidar que fueron redactados en pleno asedio de Elche y que las gestiones para consolidar la conquista de todo el reino de Murcia y someter algunas plazas rebeldes ocupaban la mente y actividad del monarca aragonés. Pero, además, faltaba obtener la licencia del papa, y esa fue sin duda una de las peticiones que Jaime II iba a elevar al pontífice durante su estancia en Roma en los primeros meses de 1297. Precisamente, el monarca eligió al abad de Santes Creus para que formara parte de la comitiva que lo acompañaría en el viaje, y por ello rogó al abad del Cister lo escusara, durante aquella coyuntura, de su presencia en el Capítulo(7).

El papa, a la sazón Bonifacio VIII, debió aprobar la iniciativa del rey, y también el abad de la Granselve y la reina Violante debieron acceder a las peticiones de Jaime II, ya que éste, el 1 de marzo de 1297, expidió la carta de donación al abad de Santes Creus, fray Bonanat de Vilaseca, de todos los bienes que unos meses antes había escogido para la nueva fundación cis- 
terciense en Murcia(8). Este documento, pues, marca la consolidación de la fundación y por él además, el rey establecía una serie de condicionantes:

- manifestaba su voluntad de que el monasterio se conociera bajo la denominación de la Virgen, característica de los monasterios del Cister: "ad honorem et laudem Omnipotentis Dei et beate Marie virginis matri sue, sub ipsius virginis vocabulo".

- daba libertad al abad y convento de Santes Creus para colocar en el nuevo monasterio el número de monjes que consideraran oportuno.

- prohibía la alienación de las posesiones concedidas, las cuales debían emplearse en el sustento del abad y convento. El rey hacía al respecto una única salvedad: el abad y convento del real de Murcia, siempre con el consentimiento del de Santes Creus, podría dar en enfiteusis algunas de las posesiones y tierras o arrendarlas por un cierto tiempo, siempre y cuando ello redundara "ad utilitatem ipsius monasterii".

- establecía firmemente la sujeción plena del nuevo monasterio al de Santes Creus, al que quedaba obligado en todo según la costumbre que la Orden del Cister establecía para los monasterios filiales.

El documento también alude a los poderes o derechos que el rey cedía al nuevo monasterio, a saber: $1^{\circ}$. El franco alodio o dominio de la tierra, "pro franco alodio", $2^{\circ}$. La concesión de franquicia para todos los bienes que le otorgaba, declarando que serían "libera et exempta", y $3^{\circ}$. El dominio jurisdiccional de las personas, "cum hominibus et feminis".

\section{1) Otras medidas}

Una vez expedidos los documentos de fundación y filiación del nuevo monasterio, tenía que procederse, en primer lugar, a la construcción del edificio que debería albergar a la nueva comunidad; para ello, el 26 de abril el rey manifestó al obispo de Cartagena su deseo de que a la erección del nuevo monasterio "celeriter procedatur", y le rogó que recibiera al abad y monjes que allí fuesen enviados y no les impidiese celebrar sus oficios divinos ${ }^{(9)}$. En segundo lugar debía efectuarse la entrega efectiva al abad de Santes Creus de todos los bienes concedidos como patrimonio de la nueva fundación, y de ello tenían que encargarse por orden del rey el procurador y baile del reino de Murcia(10).

Pero aparte de estas dos primeras medidas tendentes a asegurar el pleno dominio de los bienes que había otorgado al monasterio del Real, debía garantizarse que éste se mantuviera seguro en la sociedad que le rodeaba. Esta sociedad estaba constituida preferentemente por los habitantes de las villas y lugares asignados al nuevo monasterio, a los que ordenó 
prestasen al abad y monjes, "quos pro predictis ad vos duxerit transmitendos", el homenaje de fidelidad y les entregasen los los derechos por los bienes que tuvieran por el monasterio, igual como antes de producirse la donación a éste se los entregaban a él.(11). Este sometimiento era muy importante, por ello el rey dió instrucciones a su hermano Jaime Pérez, procurador del reino de Murcia, para que si dichos hombres se mostrasen negligentes en prestar el homenaje y juramento de fidelidad, les obligara con sus bienes(12). El abad se convertiría así en un verdadero señor feudal, característica ésta de aquella etapa decadente del monaquismo occidental, que se manifestará igualmente, como señala Ferrán García, respecto al monasterio de la Valldigna(13).

Por su parte, el abad y convento de Santes Creus, ante la favor que les había otorgado el rey y la responsabilidad de llevar a cabo la erección de un nuevo monasterio en Murcia, filial suyo, el 24 de mayo de aquel año de 1297 nombraron a los monjes fray Pere Riera y fray Valentí Carbonell, y al converso fray Arnau Demater, como procuradores para tomar posesión de los bienes concedidos, para recibir el homenaje de los habitantes de los lugares y para edificar el monasterio, en el real de Murcia, bajo la Regla del Cister; también se les concedía plena facultad para actuar y administrar en su nombre el nuevo monasterio(14). Ello indica que el abad de Santes Creus no elijió todavía a un abad para su filial murciana, sino de momento sólo a unos procuradores que, "nomine et loco nostri", debian encargarse de las gestiones encaminadas a hacer realidad el proyecto real.

\section{FRACASO DE LA FUNDACION}

Los procuradores designados debieron salir de Santes Creus en su camino hacia Murcia a finales de mayo, acompañados seguramente de los monjes que iban a constituir la primera comunidad del nuevo convento, siguiendo de esta forma las instrucciones que Jaime II había dado al abad de Santes Creus: " in quoquidem monasterio conventum assumere volumus de monachis monasterii Sanctarum Crucum".Preveyendo ya la inmediata llegada de los procuradores a Murcia, el monarca dió orden a su portero Miguel Sa Real de poner a aquellos en plena posesión de los bienes concedidos(15).

Desconocemos el número de monjes que acudieron a Murcia, lo cierto es que a partir del mes de julio la documentación habla ya de los frailes allí establecidos, seguramente en alguna dependencia provisional, aunque todavía no de un abad, puesto que, tal como hemos comentado, fue el de Santes Creus el que en aquel primer momento en que el edificio estaba en trámites de construcción, ostentó la superioridad a través de los procuradores que él mismo había designado. Sin embargo, las dificultades a las que muy pronto 
los monjes recién llegados tuvieron que enfrentarse iban a impedir el funcionamiento de una comunidad estable y jerarquizada.

En efecto, pese a las ordenanzas que, como comentamos, dirigió el rey a oficiales y eclesiásticos del reino de Murcia de acojer y ayudar a los monjes del nuevo monasterio cisterciense, ni unos ni otros las acataron. $\mathrm{Si}$, por una parte, los oficiales empezaron a exigirles servicios y exacciones contra la inmunidad de que gozaban(16), fue el obispo de Cartagena Diego Martínez Magar el que protagonizó la oposición más grave al pretender impedir la construcción del monasterio, de cuyas primeras dependencias, además, un capellán suyo se llevó todos los ornamentos eclesiásticos y otros objetos. El 23 de julio Jaime II le rogó desistiera de su oposición, permitiendo que el monasterio fuese construido y fundado e hiciera restituir todo lo robado(17).

Tres meses más tarde, según refleja la documentación, las dificultades del nuevo monasterio continuaban. Parece ser que el procurador del reino de Murcia obligaba a los monjes a contribuir en las acémilas del ejército, lo que originó su queja al rey, el cual tuvo que ordenar al procurador les restituyera los embargos que les hubiera efectuado por esta razón.(18) Pero fueron los procuradores fray Pere Riera y fray Valentí quienes pusieron en conocimiento del monarca un hecho realmente grave. Algunas personas, de diferente condición, a pesar de que en la ciudad de Murcia podían encontrar muchos lugares donde alojarse, se hospedaban en el monasterio del real sin permiso de los monjes y allí cometían muchos crímenes y actuaban desordenadamente. La situación creada, que iba "contra Cisterciensis Ordinis instituta", obligó al rey a ordenar al procurador del reino de Murcia prohibiera a las gentes, cualquiera que fuese su condición, hospedarse en el monasterio contra la voluntad de los monjes(19).

Pero el procurador no extremó su celo en obedecer las órdenes del rey, puesto que, por una parte, sabemos que de forma injusta y contra los privilegios concedidos, empezó a obligar a los sarracenos del monasterio del real de Murcia y que habitaban en las granjas de éste a contribuir por los bienes que poseían en estos lugares(20). Precisamente, la situación de aquellos sarracenos se hizo más grave cuando, al no poder habitar con seguridad en las granjas del monasterio por temor a los castellanos, algunos se refugiaron en Murcia, siendo entonces obligados por el baile y almojarife de la ciudad a pagar el cabezaje. El rey ordenó a dichos oficiales no exigieran este impuesto a los sarracenos del monasterio, puesto que quería que se sintieran seguros en ella mientras durara la guerra.(21)

Todas las instrucciones del rey no evitaron, sin embargo, que continuaran las presiones contra el nuevo monasterio, la mayor parte de cuyos bienes, a fines de aquel año, fueron embargados por el procurador de Murcia, al exigír a los frailes el pago de determinadas cantidades. Los procuradores 
del monasterio, fray Pedro Riera y fray Valentí, presentaron nuevamente querella al rey ante estas imposiciones que atentaban contra los privilegios $y$ libertades a ellos otorgados(22).

$\mathrm{Si}$, por lo que acabamos de comentar, el procurador de Murcia no puso ninguna facilidad a los monjes para asentarse cómodamente en la ciudad, tampoco los jurados y prohombres de ésta mostraron una actitud más acojedora, ya que pretendieron obligarles a contribuir en las questias y otras exacciones reales y vecinales por los bienes concedidos al monasterio, a pesar de que éstos gozaban de la condición de franquicia y a pesar de que las personas que antes las habían poseido nunca habían contribuido. Enterado el rey de este abuso, les ordenó inmediatamente que dejaran de llevar a cabo estas exigencias a los frailes del real de Murcia hasta que él acudiera a la ciudad, lo que esperaba hacer en breve(23).

El 3 de febrero de 1298, cuando el rey se encontraba en el asedio del castillo de Alhama, despachó la última carta alusiva a los monjes del monasterio murciano. Se trata de la concesión que hizo a Juan Díaz, entonces procurador de dichos monjes, así como a los sarracenos de Alcantarilla, propiedad del monasterio, de ser escusados de acudir al ejército que hacía en el reino de Murcia(24).

¿Qué sucedió tras esta concesión?. Tal como anunció a los oficiales de Murcia, Jaime II acudió pronto a la ciudad, donde lo encontramos el 6 de febrero, y tal como les prometió, debió plantearse la continuidad del monasterio. A la vista de las circunstancias Jaime II decidió su supresión, y los trámites con el abad de Santes Creus no debieron presentar dificultades. Precisamente, sabemos que éste se encontraba en Murcia a principios de marzo, adonde había acudido seguramente para tratar este asunto y también para lograr que el justicia de la ciudad le restituyera un sarraceno que, huido del monasterio del real, aquel lo capturó negándose a devolverlo.(25)

Jaime II recuperó del abad y convento de Santes Creus los bienes que les había concedido en Murcia para la fundación del monasterio, permitiéndoles, sin embargo, recaudar y percibir todos los frutos y ganancias de dichos bienes y heredades hasta la fiesta de San Juan del mes de junio. Así lo comunicó el monarca el 19 de marzo de aquel año de 1298 al procurador, bailes y a todos los oficiales y súbditos del reino de Murcia, con la orden de permitir al abad y convento de Santes Creus el cobro de dichos frutos. (26). Además, y en compensación por las obras y gastos que el abad de Santes Creus había efectuado en Alcantarilla, Alguazas y en el real de Murcia, le concedió todas las rentas procedentes de la heredad que fue de García Jofré y de su esposa María Fernández hasta la próxima fiesta de Navidad(27). Era una manera de enmendar a Santes Creus por las gestiones y desvelos a los que le había conducido al querer proyectar, sin éxito, una nueva fundación monástica. 
Llegados a este punto surge la inevitable pregunta: ¿por qué fracasó el monasterio del real de Murcia?.

Aunque no poseemos un texto que lo indique, es aceptable la opinión de Ferrán García de que la débil consolidación del dominio de Aragón sobre Murcía sería la explicación que cabría aventurar; sin embargo, tomando esta premisa como base y planteando una serie de consideraciones, podemos aducir razones mucho más precisas que se deducen de todo lo expuesto.

Jaime II proyectó el monasterio del real de Murcia apenas dos meses después de haber logrado la capitulación de la ciudad y de haber establecido las bases de su organización administrativa. Las medidas tomadas para consolidar su poder creaban un ambiente propicio para la instalación del nuevo monasterio, al que además el monarca otorgó todo su apoyo. Por otra parte, las características de los bienes que concedió al monasterio eran inmejorables. Baste considerar, por ejemplo, el real de Monteagudo con sus viñas y secano, o Alguazas, regada por las aguas del Mula y del Segura que aseguraban los riegos y el abastecimiento del agua, indispensable para la vida conventual, y Alcantarilla, cuya situación en la huerta garantizaba también a los monjes un buen rendimiento de sus tierras. Así pues, creo que la inviabilidad del monasterio del real de Murcia lo hemos de buscar en la falta de los condicionantes exigidos por la regla del Cister. Tres son las causas que parecen deducirse de la documentación: falta de aislamiento, carencia de seguridad y mala acogida.

- Falta de aislamiento. La primera condición impuesta por la Regla del Cister era la soledad absoluta, lejos de ciudad o aglomeración humana, obligación que, según Cocheril, fue la causa del traslado de muchos monasterios(28). El emplazamiento del monasterio del real de Murcia no cumplía este requisito. Situado en la capital, hemos visto como en octubre de 1297 los procuradores del monasterio tuvieron que denunciar la intromisión de nobles y caballeros que se hospedaban en él, viviendo allí desordenadamente contra la voluntad de los frailes. La problemática que debian plantear estos intrusos no garantizaba una vida de oración y recogimiento a la que los monjes estaban obligados.

-Carencia de seguridad. Pese a la conquista, los lugares otorgados al monasterio del real no estarían suficientemente protegidos y el temor a los castellanos fue la razón, como hemos comentado, de que los sarracenos de las granjas del monasterio se trasladaran a Murcia en busca se mayor seguridad. La huída de estos mudéjares de las zonas de cultivo de los frailes, privaba a éstos de su principal mano de obra.

- Mala acojida. Los monjes llegados a Murcia no fueron bien aceptados por parte del sector ecclesiástico. Ya hemos comentado la actitud de rechazo del obispo de Cartagena, tal vez por temor a que la presencia de los frai- 
les en la ciudad, protegidos por el monarca, hiciera peligrar algunas de sus prerrogativas. Mala acogida asimismo por parte del sector político, pues, como podemos constatar por la documentación, las imposiciones, exigencias y abusos por parte del procurador, baile, oficiales y prohombres fueron constantes.

En resúmen, fueran éstas $u$ otras las causas, lo cierto es que el monasterio del real de Murcia no pasó de ser un proyecto apenas puesto en práctica. Sin embargo, Jaime II no quiso renunciar a ser el promotor de una fundación monástica y por ello, tan pronto fue consciente del fracaso de la fundación emprendida en Murcia, inició las gestiones encaminadas a la creación de un nuevo monasterio. En aquella ocasión el éxito le acompañó y el 15 de marzo de aquel mismo año de 1298 empezaba la historia de una nueva fundación cisterciense que, bajo el nombre de Santa María de Validigna, todavía hoy es una realidad. Con ella su proyecto murciano quedaba ya definitivamente en el olvido.

\section{APÉNDICE DOCUMENTAL}

\section{1}

1296, julio, 4. Asedio de Elche.

Jaime II comunica a Rufino, abad del Cister, y a todo el capítulo de la Orden su intención de fundar un monasterio cisterciense en la ciudad de Murcia, filial de Santes Creus. Les pide le otorguen su consentimiento y consejo para llevar a cabo este proyecto.

ACA, C, reg. 340 , fol. $194 \mathrm{r}$.

Venerabilibus ac religiosis viris dompno [Ruf]ino], abbati Cisterciensis, ac universis abbatibus eius Ordinis in generali capitulo congregatis, Jacobus, Dei gratia et cetera.

Cum nos propter dilectionis ac devotionis magne afectum quem progenitores nostri et nos erga Ordinem vestrum et specialiter erga monasterium Sanctarum Crucum, ubi corpus excellentissimi domini Petri inclite recordationis regis Aragonum patris nostri quiescet et in quo etiam nostram elegimus sepulturam, habuerunt et nos habuimus hactenus et habemus, intendamus ipsum Ordinem honorare et personarum eiusdem numerum ob ampliorius divini cultus intuitum augmentare, ad honorem domini nostri Ihesu Christi et beatissime virginis matris eius et salutem anime nostre et parentum nostrorum, in remissionem nostrorum omnium peccatorum in regno Murcie quod, disponente Domino et iuvante me de novo submisimus dicioni, monasterium 
vestri Ordinis apud civitatem Murcie ordinavimus noviter construendum, pro cuius fundatione et donatione ac fratrum seu personarum ibidem Domino famulantium sustentatione satis competentes possessiones et redditus duximus assignandos, in quoquidem monasterio conventum assumere volumus de monachis monasterii Sanctarum Crucum predicti. Verum, quia predicta fieri velimus et intendimus de vestro consilio et assensu universitatis vestre, religionem in Domino deprecamur ac etiam exortamur quatenus, [habet] pie devotionis nostre et rei tam favorabili annuentes et assensum vestrum prebentes, pro predictis perficiendis ac complendis faciatis ea que per nos facienda noveritis et secundum Deum expedire videritis iuxta vestri Ordinis instituta et, licet credamus in vestris orationibus vos non esse inmemores domus nostre, nichilominus vos sollicitantes religionis vestre sanctitatem duximus exorandam quatenus animas parentum nostrorum, nos et regna nostra recomendatas habeatis in orationibus vestris factis, ordinantis in vestro capitulo ut per omnes domos vestri Ordinis specialis pro nobis oratio fratribus iniungatur nobis, si placet quod nobis super predictis videbitur rescribentes.

Datum in obsidione Eltxii, IIIIำ nonas iulii, anno Domini $\mathrm{M}^{\circ} \mathrm{CC}^{\circ} \mathrm{X} \mathrm{C}^{\circ} \mathrm{V} \mathrm{V}^{\circ}$.

\section{2}

1296, julio, 4. Asedio de Elche.

Jaime II da a conocer todos los bienes que ha asignado para la fundación de una abadía de la Orden del Cister en Murcia, filial de Santes Creus.

ACA, C, reg. 340, fol. 195r.

Nos Jacobus, Dei gratia rex Aragonum, Maiorice, Valentie et Murcie ac comes Barchinone, assignavimus ad fundandam abbatiam Cisterciensis Ordinis apud Murciam, quam volumus esse filiam monasterii Sanctarum Crucum, bona que secuntur, que dicuntur esse domine regine Castelle, amite nostre:

Primo, regale quod est apud Murciam, cum orto, domibus, balneis et aliis suis pertinentiis universis; affrontant hec omnia de duabus partibus cum muro civitatis, de tertia in mercato, de quarta cum orto Simonis, cristaler, et possunt hec valere in redditibus annuatim M CC morabetinis de paga Castelle.

Item, Alcantarenella, cum terminis, iuribus et pertinentiis suis universis; affrontant de Levante cum Petro Barca, cum Raimundo Felicis et cum terra que fuit lohannis Hivayes quondam, et a parte occidentis cum podio quod est ultra barrancum salinarum, et a meridie ab la Dauna, et ab aquilone cum 
territorio de Molina Seca et cum rivo Secura. Valet in redditibus annuatim MMM D morabetinis de paga Castelle.

Item, regale et terram Montisacuti, cum iuribus et pertinentiis suis universis sicut affrontat a meridie cum Amargali, axí com és lo canalo gros, a circio cum vineis dels balesters, ab oriente sicut vergunt et fluunt aque de serra, et de occidente cum Alabraix. Potest valere in reditibus annuatim MM morabetinis de paga Castelle.

Item, Alguastam de Molina, cum suis iuribus et pertinentiis. Affrontat ab oriente in rivo de Segura, et ab occidente in rivo de Mula, et a meridie in dicto rivo de Segura, et a circio cum Cepti. Valet in redditibus MMMMD morabetinis de paga Castelle.

Item, hereditatem domine Marie Ferrandiç, uxoris quondam Garcie Jofre, cum regali et domibus eiusdem et cum iuribus et pertinentiis universis, sicut affrontat ab oriente in via del Algaçar, et ab occidente in camino de Rofayma, excepta una pecia terre quam ibi habet Arnaldus Çaguda et uno trocio terre den Claret quod est in medio contiguum cequie mediane et alio trocio terre Petri de Uluga sub cequia mediane, cum terra Petri Barce et cum vineis den Salvetat, et de circio cum prima cequia et cum rambla. Valent in redditibus MMMM morabetinis de paga Castelle.

Item, medietatem molendinorum del alcaçer et cum Filat Aptata. Valent MM morabetinis de paga Castelle in redditibus singulis annis, et in testimonium predicte assignationis presentem litteram nostro sigillo fecimus sigillari.

Datum in obsidione de Eltx, IIIIำ nonas iulii anno predicto $\left[\mathrm{M}^{\circ} \mathrm{C} \mathrm{C}^{\circ} \mathrm{XC}^{\circ} \mathrm{VI}^{\mathrm{a}}\right]$.

\section{3}

1297, marzo, 1. Roma.

Jaime II concede a fray Bonanat, abad de Santes Creus, licencia para construir un monasterio del Cister, filial suyo, en la ciudad de Murcia, para cuya construcción y sustento de los monjes le otorga una serie de bienes.

ACA, C, reg. 321 , fols. $43 r .-44$ r.

In Christi nomine. Noverint universi quod nos Jacobus, Dei gratia rex Aragonum, Maiorice, Valentie et Murcie comesque Barchinone ac sancte Romane Ecclesie vexillarius, amirantus et capitaneus generalis, habentes specialis devotionis affectum erga orationes et elemosinas et alia bona opera que in monasterio Sanctarum Crucum Cisterciensis Ordinis in Cathalonia per fratrem Bonanatum, nunc abbatem, et conventum eiusdem monasterii continue 
frequentantur et etiam ibidem nos et serenissima regina domina Blanca, coniux nostra, elegerimus sepulturam, considerantes etiam provide quod inter cetera opera karitatis que hominem amabilem et proximum Deo reddunt edifficare monasteria, ecclesias et alia loca ecclesiastica in quibus magestas Altissimi colandetur non modicum locum tenent, idcirco dignum duximus deputandum ut in hac parte transitoria pro eternis et caduca pro celestibus salubriter comutantes, ad honorem et laudem omnipotentis Dei et beate Marie virginis matris eius et totius curie celestis, in civitate Murcie, in loco cognominato Regali, unum monasterium Cisterciensis Ordinis, quod filiam dicti monasterii Sanctarum Crucum existere volumus, nostro suffragante auxilio erigatur, in quo cultus vigeat et crescat divini nomine ac ipsius et aliorum sanctorum suffragia a Christi fidelibus devote ac humiliter implorentur. Hiis igitur devote pensatis, auctoritate regia concedimus dicto fratri Bonanato, abbati, et conventui dicti monasterii ut in dicta civitate Murcie et dicto loco eiusdem, ad honorem et laudem omnipotentis Dei et beate Marie virginis matris sue, sub ipsius virginis vocabulo secundum regulas Cisterciensis Ordinis, erigant, edifficent et etiam construant, ad cuius quidem constructionem et personarum que in eodem pro tempore degent sustentationem et alia eorum necessaria concedimus, tradimus et donamus pro franco alodio, constituentes nos ipsius monasterii nomine, possidere, terras, possessiones, loca et bona et redditus infrascriptos, cum hominibus et feminis et omnibus edifficiis, pascuis, aquis et aqueductibus, planeis et arboribus cuiuslibet generis, ingressibus et exitibus et omnibus aliis iuribus universis, scilicet Regale predictum situm in civitate Murcie, cum orto, domibus, balneis et aliis suis iuribus et pertinentiis universis, sicut affrontatur hec de duabus partibus cum muro civitatis, de tertia in mercato, de quarta cum orto Simonis, cristeller. Item Alcantarellam, cum terminis et iuribus et suis pertinentiis universis, sicut affrontatur ab oriente cum honoribus Petri Barca et cum honoribus Raimundi Felicis et cum quedam terra que fuit Johannis Ivanyes quondam, ab occidente autem affrontatur cum podio quod est ultra barrancum salinarum, et a meridie ab la danua, et ab aquilone cum termino de Molina Sicca et cum rivo Segura. Item regale et terram Montisacuti, cum iuribus et pertinentiis universis, sicut affrontatur a meridie in Armaiali, "axi com es 10 Canaylo gros", a circio cum vineis ballisteriorum, ab oriente sicut fluunt aque de Secura, et ab occidente cum albrarum. Item Alguastam de Molina, cum suis pertinentiis et iuribus universis, sicut affrontatur ab oriente in rivo de Segura et a circio cum Septi. Item hereditatem que fuit Marie Ferrandis, uxoris quondam Garcie Joffre, cum regali et domibus eiusdem et cum iuribus et pertinentiis universis, sicut affrontatur ab oriente in via Dalgepsar et ab occidente in camino de Roffaymia, excepta una pecia terre quam ibi habet Arnaldus Saguda, et uno trocio terre den Claret, quod est in medio contiguum cequie mediane, et alio trocio terre Petri de Oliva sub cequia mediana, a meridie cum terra Petri Barca et cum vineis den Salvetat, et a circio cum prima cequia et cum Rambla. Item medietatem molendinorum de alcaser. 
Quas quidem possessiones, redditus et bona omnia a nobis dicto monasterio concessa et tradita sic esse volumus omnia libera et exempta ut ratione seu occasione ipsorum omnium predictorum non teneatur dictum monasterium solvere seu exhibere aliquas tallias, collectas, pedagia, pensum, subsidia nec etiam alicuius exactionis seu muneris extraordinarii et etiam ordinarii, realis et etiam personalis generi sit astrictum, nec etiam de cetero in premissis vel aliqua alia servitute regie subiaceant potestati. Predicta in qua tali modo et forma damus et concedimus predicto monasterio noviter construendo quod abbas et conventus monasterii predicti Sanctarum Crucum ponant et instituant ibi ac ponere et instituere teneantur conventum sufficientem monacorum quibus preficiatur abbas, qui in perpetuum iuxta eiusdem Ordinis observantiam ibidem Altissimo famulentur secundum quod in Ordine Cisterciensis est fieri consuetum, et quod in edifficatione et erectione monasterii construendi, modis quibus poterunt, intendant et dent operam efficacem. Volumus etiam et firmiter statuimus quod res predicte per nos date vel aliqua earundem nunquam possint alienari vel in qualibet personan transfferri, sed eas et earum quaslibet pro sustentatione abbatis et conventus et aliarum personarum in ipso monasterio degentium in iure et proprietate ipsius monasterii perpetuo remanere. Alioquin exnunc ut extunc alienationem ipsam ex certa scientia decernimus irritam et inanem et carere viribus et valore, ita quod nos et successores nostri in regno Murcie res alienatas possimus in continenti de facto possessoribus earum auferre et eas reducere ad ius et proprietatem monasterii supradicti, alienatione inde facta in aliquo non obstante, salvo quod abbas et conventus eiusdem monasterii, cum consensu tamen abbatis Sanctarum Crucum, servata forma legitima, possint ad utilitatem ipsius monasterii aliquas ex possessionibus et terris predictis in emphiteosim dare vel ad certum tempus locare. Volumus etiam ac firmiter statuimus quod monasterium ipsum noviter construendum monasterio Sanctarum Crucum predicto perpetuo sit subiectum et quod teneatur sibi ea omnia facere que iuxta consuetudinem Cisterciensis Ordinis subiecta monasteria sunt consueta, quibus subsunt monasteriis exhibere. Mandamus insuper procuratoribus, baiulis, curiis, iustitiis et universis aliis officialibus et subditis nostris, presentibus et futuris, quod predicta omnia et singula firma habeant et observent et non contraveniant nec aliqua contravenire permitant aliqua ratione.

Datum Rome, kalendis martii, anno Domini millesimo, ducentesimo, nonagesimo sexto.

Signum Jacobi, Dei gratia regis Aragonum, Maiorice, Valentie et Murcie comitisque Barchinone ac Sancte Romane Ecclesie vexillarii, amiranti et capitanei generalis.

Testes sunt: [ $1^{\mathrm{a}}$ col.] Arnaldus episcopus Dertusensis.- $\left[2^{\mathrm{a}}\right.$ col.] Raimundus Alamanni.- Petrus de Queralto.- [3 $\left.3^{a} \mathrm{col}.\right]$ Eximinus Petri de Arenoso.- Acardus de Muro.

1297, abril, 26. Barcelona. 
1297, julio, 23. Lérida.

Jaime II, enterado de que el obispo de Cartagena Diego [Martínez Magar] pretende impedir la construcción del monasterio que ha establecido en Murcia, ruega a éste no ponga obstáculos y haga restituir a los monjes los ornamentos y demás objetos que un capellán suyo les robó.

ACA, C, reg. 108, fol. 159v.

Venerabili et dilecto Didico, per eandem episcopo Cartaginensi, et cetera.

Cum nos ad honorem omnipotentis Dei et gloriose Marie virginis matris sue in civitate Murcie, obtenta licentia a domino summo pontifice, monasterium Ordinis Cisterciensis providerimus noviter construendum et vos, ut intelleximus, ipsius monasterii constructionem nitamini impedire, ideo vos expresse requirimus et attente rogamus quatenus, a dicto impedimento penitus desistentes, permitatis dictum monasterium libere et absque alicuius contrarietatis obstaculo construi et fundari, exhibentes vos monachis et personis in dicto monasterio comorantibus favorabilem et benignum, nullam eis aut bonis dicti monasterii molestiam inferendo, restituendo insuper et faciendo restitui monachis supradictis omnia ornamenta ecclesiastica et alia que quidam capellanus vester a dicto monasterio asportavit.

Datum llerde, $\mathrm{X}^{\circ}$ kalendas augusti [anno $\mathrm{XC}^{\circ} \mathrm{VII}^{\circ}$ ].

5

1297, octubre, 30. Teruel.

Jaime II, enterado por los procuradores del monasterio del real de Murcia de que algunos se hospedan en él sin pedir permiso a los monjes, $y$ alli cometen crímenes y acciones que atentan contra los preceptos del Císter, ordena al procurador del reino de Murcia prohiba el hospedaje en el monasterio sin voluntad de los monjes y defienda a éstos de toda violencia y agravio.

ACA, C, reg. 106, fol. 91r.

Procuratori regni Murcie vel eius locumtenenti, et cetera.

Ex parte fratris Petri de Riaria et fratris Valentini Cisterciensis Ordinis, procuratorum monasterii de Regali Murcie, conquerendo propositum extitit coram nobis quod aliqui, tam nobiles, milites quam alii, licet in civitate Murcie possent plura hospicia invenire, monaschis eiusdem monasterii invitis et irre- 
quisitis, in dicto monasterio hospitantur. Verum, cum per dictos hospites ibidem, ut asseritur, plura et turpia crimina comittantur ac etiam inordinate sue satisfaciant voluntati, quod est contra religionem ipsorum ac Cisterciensis Ordinis instituta, quare fuit nobis humiliter suplicatum ut super hiis dignaremur eisdem de iuris remedio providere. Suplicatione ipsa benigne admisssa, vobis dicimus et mandamus quatenus prohibatis et prohiberi etiam faciatis ne aliqui, tam nobiles, milites, quam alii in dicto monasterio contra voluntatem dictorum monachorum hospitentur, manutenendo et deffendendo eosdem contra quoscumque inferentes seu inferre volentes eisdem super predictis violentiam aliquam seu gravamen.

Datum ut supra [Turolii, $111^{\circ}$ kalendas novembris, anno Domini $\mathrm{M}^{\circ} \mathrm{CC}^{\mathrm{o} X \mathrm{XC}^{\mathrm{o}} \mathrm{VII}}$ ].

Raimundus Caprarii.

\section{6}

1297, diciembre, 9. Valencia.

Jaime II, al saber por fray Valentino, procurador del monasterio del Cister en Murcia, que los jurados y prohombres de esta ciudad obligan a dicho monasterio a contribuir con ellos en las questias y demás exacciones reales y vecinales, a pesar de que él ha concedido estos bienes al monasterio, francos y libres, ordena a aquellos desistan de esta imposición hasta que él acuda a esta ciudad y decida sobre ello.

ACA, C, reg. 106, fol. 135v.

lustitie, iuratis et probis hominibus Murcie, et cetera.

Intelleximus per fratrem Valentinum, procuratorem monasterii quod nos in civitate Murcie de Ordine Cisterciensis construhi et edifficari providimus, quod vos compellitis et compellere intenditis procuratorem ipsum et bona per nos data et assignata ad constructionem et sustentationem dicti monasterii et fratrum eiusdem ad contribuendum et ponendum vobiscum in questiis et aliis exactionibus regalibus et vicinalibus, licet illi quorum ipsa bona fuerunt nunquam in aliquibus exactionibus vobiscum, ut asseritur, pro bonis ipsis contribuerunt et licet nos ipsa bona dicto monasterio concesserimus francha et libera ab omnibus muneribus et exactionibus, super quibus per procuratorem predictum fuit nobis humiliter suplicatum sibi et dicto monasterio de opportuno remedio provideri. Nos autem, volentes super hiis salubre remedium impartiri, vobis dicimus et rogamus quatenus a compellendo procuratorem predictum et bona dicti monasterii ad contribuendum vobiscum in pre- 
dictis supersedeatis omnino quousque nos in ipsis partibus, in quibus in brevi esse disponimus, Deo dante, fuerimus personaliter constituti, tunc enim nos taliter super hiis providerimus quod ius vestrum et dicti monasterii utrique parti remanebit illesum.

Datum Valentie, $V$ o idus decembris [anno $M^{\circ} \mathrm{CC}^{\circ} \times \mathrm{C}^{\circ}$ septimo]. Guillermus de Solanis.

\section{7}

1298, marzo, 19. Játiva.

Jaime II comunica al procurador, baile y a todos los oficiales y súbditos del reino de Murcia que, a pesar de que ha recobrado del abad y convento de Santes Creus los lugares y heredades que les habia dado en el reino de Murcia, les ha concedido poder recaudar y percibir las rentas de dchas posesiones hasta la fiesta de San Juan del mes de junio, por lo que les ordena se lo permitan hacer.

ACA, C, reg. 264, fol. 245r.

Dilectis et fidelibus suis procuratori, baiulis, iustitiis et universis aliis officialibus et subditis suis in regno Murcie constitutis ad quos presentes pervenerint et cetera.

Noveritis nos concessisse abbati et conventui Sanctarum Crucium quod, licet nos recuperavimus ab eis loca et hereditamenta sita in regno Murcie que ipsis contuleramus, habeant et colligant et percipiant omnes fructus et expleta ipsorum hereditamentorum proventura usque ad festum Sancti lohannis iunii proxime venturum in eorum usibus convertenda. Quare vobis dicimus et mandamus quatenus fructus et expleta hereditamentorum predictorum que inde provenient usque in dicto festo permitatis per dictum abbatem et conventum seu per quem voluerint loco sui colligi et levari sine aliquo contradictu.

Datum Xative, XIIII-kalendas aprilis, anno predicto

[ $\mathrm{M}^{\circ} \mathrm{CC}^{\circ} \mathrm{X} \mathrm{C}^{\circ}$ septimo]. 


\section{NOTAS}

(1). Se denominaba real "la zona montuosa o de secano cercana a territorio de regadío y de no mucha extensión, con características peculiares que hacian posible su fácil diferenciación o delimitación de las tierras vecinas...": Juan TORRES FONTES, Repartimiento y Repoblación de Murcia en el siglo XIII, Murcia, 1990, pág. 55.

(2). Ferran GARCIA, El naixement del monestir cistercenc de la Valldigna, València, 1983, págs. $45-47$ y doc. I.

(3). "Verum, quia possessiones quasdam et res alias per dompnum Alfonsum bone memorie regis Castelle cuidam monasterio in civitate predicta per eundem antiquitus constructo concessas, per dompnum Sancium eius filium, qui monasterium destruyt, alienatas invenimus et in pluris distributas...": ACA, C, reg. 340, fols. 193v.-194r.

(4). Apéndice, núm. 1.

(5). ACA, C, reg. 340, fol. 194r.-v.

(6). Apéndice, núm. 2.

(7). ACA, C, reg. 340, fol. 194v. (1296, julio, 4).

(8). Apéndice, núm. 3.

(9). ACA, C, reg. 321 , fol. $61 \mathrm{v}$.

(10). ACA, C, reg. 321, fols. 60v.-61r. (1297, abril, 27).

(11). "eisdem respondeatis de omnibus de quibus nobis respondere tenebamini ante donationem predictam": ACA, C, reg. 264, fols. 19v.-20r. (1297, mayo, 20).

(12). ACA, C, reg. 108, fol. 34v. (1297, mayo, 21).

(13). Ferran GARCIA, ob.cit., pág. 69.

(14). Ibidem, doc. I.

(15). ACA, C, reg. 195, fol. 19r.-v. (1297, mayo, 29).

(16). Jaime II tuvo que ordenar a sus oficiales no exigieran a los frailes del real de Murcia ninguna cena, servicio ni exacción: ACA, C, reg. 108, fol. 152v. (1297, julio, 21).

(17). Apéndice, núm. 4.

(18). ACA, C, reg. 106, fol. 91r. (1297, octubre, 30).

(19). Apéndice, núm. 5.

(20). El monarca ordenó al procurador no obligara a los sarracenos del monasterio del real a contribuir, y prohibiera al maestro Bernardo, almojarife de los sarrace- 
nos de la Arrixaca, embargar a los sarracenos del monasterio: ACA, C, reg. 106, fol. 91 r.-v. (1297, octubre, 30).

(21). ACA, C, reg. 106, fol. 135r. (1297, octubre, 10).

(22). ACA, C, reg. 106, fol. 111v. (1297, noviembre, 28).

(23). Apéndice, núm. 6.

(24). ACA, C, reg. 256, fol. 31r.-v.

(25). ACA, C, reg. 107, fols. 293v.-294r. (1298, marzo, 12).

(26). Apéndice, núm. 7.

(27). ACA, C, reg. 110, fol. 53r.-v. (1298, marzo, 31).

(28). P. Maur COCHERIL, "L'implantation des abbayes cisterciennes dans la Péninsule lbérique”, “Anuario de Estudios Medievales” I (1964) págs. 256 y ss. 